\title{
Are essay mills committing fraud? A further analysis of their behaviours vs the 2006 fraud act (UK)
}

\author{
Michael J. Draper ${ }^{*}$ and Callum Reid-Hutchings
}

\author{
* Correspondence: m.j.draper@ \\ swansea.ac.uk \\ Hillary Rodham Clinton School of \\ Law, Swansea University, Singleton \\ Park Campus, Swansea, UK
}

\begin{abstract}
Many strategies have been proposed to address the supply of bespoke essays and other assignments by companies often described as 'Essay Mills' with the act of supply and use being invariably described as 'contract cheating'. These proposals increasingly refer to the law as a solution in common with other action. In this article, the lead author revisits work undertaken in 2016 as a result of recent legal and extra-legal developments to assess whether the UK Fraud Act (2006) might now be used to tackle some of the activities of the companies involved, by comparing their common practises, and their Terms and Conditions, with the Act. It was previously found that all sites have disclaimers regarding the use of their products but there were some obvious contradictions in the activities of the sites which undermined those disclaimers, for example plagiarism-free guarantees for the work. In this article, we ask and consider the question whether this is still the case having regard to the impact of a change in the law by the UK supreme court and recent action of the UK Advertising Standards Authority. We also consider whether a call for a new offence to be created which specifically targets the undesirable behaviours of these companies is still justified.
\end{abstract}

Keywords: Contract cheating, Plagiarism, Fraud essay mill, Fraud act, QAA, ASA

\section{Main text}

In this article we consider the development of law and policy in the area of contract cheating and in particular, whether or not recent changes in UK law, action taken by the Advertising Standards Authority and the guidance issued by the Quality Assurance Agency for the UK (QAA 2016, QAA 2017) have had an impact on the knowledge and state of mind of UK registered companies engaged in supplying essays to students for financial gain and the consequences for the operation of the Fraud Act 2006.

Our findings in relation to the action taken by the Advertising Standards Authority have a wider implication for the current debate in relation to proposed legislative responses to contract cheating across the common law world, in particular Australia and the Republic of Ireland.

In earlier work, Draper et al. (2017), and Draper and Newton (2017) considered the main actors in contract cheating: a student, their university, and a third party (often a company or 'Essay Mill') who completes assessments for the former to be submitted to

(c) The Author(s). 2019 Open Access This article is distributed under the terms of the Creative Commons Attribution 4.0 International License (http://creativecommons.org/licenses/by/4.0/), which permits unrestricted use, distribution, and reproduction in any medium, provided you give appropriate credit to the original author(s) and the source, provide a link to the Creative Commons license, and indicate if changes were made. 
the latter, but whose input is not permitted. They also considered the legal consequences that might apply to such arrangements. Those legal consequences focussed on the operation of the Fraud Act 2006 and the relationship with the legal test of dishonesty necessary to establish criminal liability on the part of an Essay Mill under that Act.

Since the original work was undertaken there have been several critical developments in relation to essay mills in the UK. As noted above these involve a change in the law on dishonesty, action taken by the Advertising Standards Authority and guidance published by the quality assurance agency for the UK.

We undertook further and new research to update and expand upon our 2016/2017 findings to determine whether or not these developments have had an impact in the manner in which Essay Mills operate. Given the potential consequences of continuing to operate as usual in the context of these developments we thought it reasonable to assume that a fundamental change to the business model of Essay Mills and the terms and conditions under which they operate would be evident.

\section{Assessing guilty minds}

New case law has demonstrated and reaffirmed how knowledge may be attributed to Essay Mill companies in order to determine their potential criminal liability. Criminal liability usually requires that the defendant have a guilty state of mind, a criminal mental element which lawyers call 'mens rea'.

The Fraud Act 2006 (UK Government E 2006) has 16 sections but one general offence of fraud which may be committed in 3 principal ways:

(a) section 2 (fraud by false representation),

(b) section 3 (fraud by failing to disclose information), and

(c) section 4 (fraud by abuse of position).

The guilty state of mind necessary to secure a successful prosecution for the purposes of these sections is focussed on the dishonesty, intention and knowledge of the perpetrator. As Essay Mills tend to operate commercially through a company demonstrating that a company has a guilty state of mind is essential if a criminal prosecution is to succeed. The knowledge of the directors and other principal officers of an Essay Mill must be attributable to the company and this critical issue has recently been considered by the UK Supreme court.

In Jetvia v Bilta (2015, UKSC 23) the Supreme court determined when the knowledge of a director will be imputed to the company. The court held that imputation is sensitive to the particular facts of any case but as a matter of general principle the knowledge of a director will usually be imputed to a company when considering whether a company has committed a criminal offence.

Of particular relevance to our discussion are the observations of Lord Sumption:

"English law might have taken the position that a company, being an artificial legal construct, was mindless. If it had done that, then legal wrongs which depended on proof of some mental element such as dishonesty or intention could never be attributed to a company and the present question could not arise ... .. It cannot be emphasised too strongly that neither in the civil nor in the criminal context does this 
involve piercing the corporate veil. It is simply a recognition of the fact that the law treats a company as thinking through agents, just as it acts through them."

That the law treats a company as thinking though agents is reinforced by section 12 of the Fraud Act 2006 which provides that an offence is committed by a company if the offence is proved to have been committed with the consent or connivance of a director, manager, secretary or other similar officer of the company. Importantly the section goes on to provide that such individuals are also guilty of the offence and liable to prosecution and punishment.

Therefore human agents such as directors of an Essay Mill cannot escape liability and prosecution under the Act by hiding behind corporate personality and action claiming that the guilty mind and action is that of the company and not theirs.

Furthermore those directing the operation of Essay Mills should note that a company may take civil action against its directors for any loss suffered by the company as result of the actions of its directors.

The key question 'When the directors of a company involve it in a fraudulent transaction, is the company barred by the doctrine of illegality from suing them and their accessories for losses caused by their breach of fiduciary duty?' has been answered by Jetivia $\mathrm{v}$ Bilta with an emphatic 'No'.

The fiduciary duty of a director is to act in the best interests of the company in circumstances of absolute trust and loyalty. Consequently directors of Essay Mills are on notice that if a company suffers loss as a result of a breach of the law the company may take action legal against those directing or operating the company to recover its losses as they have failed to act in the best interests of the company. A Director cannot claim that their knowledge is attributed to a company and therefore provides a defence of corporate illegality in any action brought by the company against a director for wrongdoing.

Jetvia v Bilta also confirmed that s.213 of the Insolvency Act 1986 (UK Government E 1986, which allows liquidators to seek a contribution from any person who was knowingly party to fraudulent trading by the company) has extra-territorial effect. Claims may be brought against any person across the globe "at least to the extent of applying to individuals and corporations resident outside the United Kingdom."

Draper et al. 2017 called for the creation of a specific criminal offence in relation to Essay Mills that had extraterritorial effect because many Essay Mills are legally established outside of the UK but operate within the UK through digital services and platforms.

The case therefore supports the argument that in cases of fraud both the law and the courts will not object on the grounds of principle and are capable of facilitating a criminal prosecution in relation to activity taking place outside of a legal jurisdiction, provided there is an established relationship or activity with the legal jurisdiction in question.

\section{New law of dishonesty}

Having established that both a company and its directors and principal officers may be held liable for criminal activity through the construct of a guilty mind, we turn now to consider how the legal test for dishonesty in the UK has fundamentally altered and the 
consequential potential impact on the liability of Essay Mills and their agents under the Fraud Act.

The Explanatory Note to the Fraud Act 2006 states:

"Section 2 makes it an offence to commit fraud by false representation. Subsection (1)(a) makes clear that the representation must be made dishonestly. This test applies also to sections 3 and 4. The current definition of dishonesty was established in $R v$ Ghosh [1982] Q.B.1053. That judgment sets a two-stage test. The first question is whether a defendant's behaviour would be regarded as dishonest by the ordinary standards of reasonable and honest people. If answered positively, the second question is whether the defendant was aware that his conduct was dishonest and would be regarded as dishonest by reasonable and honest people."

In the article 'Are Essay Mills committing fraud? An analysis of their behaviours vs the 2006 Fraud Act (UK) (Draper et al. 2017) the difficulties of using the Fraud Act 2006 to take action against Essay Mills was demonstrated primarily because Essay Mills protect themselves in their terms and conditions by stating that their products are only to be used as a 'reference work' or equivalent, and must not to be submitted as the student's own work.

Thus, the second question of R v Ghosh (1982, 1 QB 1053), whether the defendant was aware that conduct was dishonest etc., would probably not be satisfied.

The UK Supreme Court in Ivey $v$ Genting Casinos (2017, UKSC 67) has revisited the test of dishonesty with significant consequences for the Fraud Act and Essay Mills.

The court has removed the subjective second question of the test for dishonesty and adopted a refined and straightforward test: does the relevant conduct fall below an objective standard of honesty?

In our view, Essay Mills should have been alerted by this decision to the fact that behaviour will now be judged to be "honest" or "dishonest" simply by the objective standards of ordinary, reasonable and honest people. In particular, the guidance given in Ivey by Lord Hughes on the application of the test of dishonesty in relation to criminal offences should be noted:

"When dishonesty is in question the fact-finding tribunal must first ascertain (subjectively) the actual state of the individual's knowledge or belief as to the facts. The reasonableness or otherwise of his belief is a matter of evidence (often in practice determinative) going to whether he held the belief, but it is not an additional requirement that his belief must be reasonable; the question is whether it is genuinely held. When once his actual state of mind as to knowledge or belief as to facts is established, the question whether his conduct was honest or dishonest is to be determined by the fact-finder by applying the (objective) standards of ordinary decent people. There is no requirement that the defendant must appreciate that what he has done is, by those standards, dishonest."

The above analysis of dishonesty was strictly speaking not a binding part of the decision but offered up by way of explanation. However the analysis is important as it points in the strongest terms to a significant change from the previous standards of dishonesty. The clear intention of the Supreme Court means that trial judges may adopt 
the Ivey test of dishonesty on the assumption that the Court of Appeal would prefer Ivey over Ghosh, as was acknowledged in DPP v Patterson (2017, EWHC 2820).

Indeed this approach has now been approved by the Court of Appeal in the 2019 case of Group Seven Limited \& Ors v Notable Services LLP \& Orsin (2019, EWCA Civ 614). As we discuss in further detail later on this means that a finding of dishonesty in relation to Essay Mills is more likely because they will simply be judged by an objective standard of dishonesty.

However will Essay Mills persist in relying on their terms and conditions as an 'industry' wide standard providing them with a defence against an allegation of dishonest practice?

Most likely they will but the recent case of Carr v Formation Group (2018) confirms that this will not be a viable defence. Under the old test for dishonesty, it was possible to call expert evidence to show that conduct, however dishonest, was 'market practice' (or that 'everybody was doing it') in order to demonstrate a lack of subjective appreciation that it fell below an objective standard of dishonesty.

Morgan J explained that this could result in some significant consequences for the proper conduct of business. As he succinctly put it in the judgment (at paragraph 32):

"The history of the markets have shown that, from time to time, markets adopt patterns of behavior which are dishonest by the standards of honest and reasonable people; in such cases, the market has simply abandoned ordinary standards of honesty."

In other words, it would be perverse to let "markets" decide their own interpretation of honesty and then be judged by that." The defence of 'everybody in this was doing it' is no longer available and this will have an impact across a wide range of industries such as Essay Mills where ordinarily 'dishonest' or misleading working cultures and practices have developed.

These practices are often most visible by the advertising employed by businesses and we now turn to developments in this area as a result of action taken by the UK Advertising Standards Authority ('ASA') in relation to the advertising of Essay Mills.

\section{ASA rulings}

Since July 2016, there have been three referrals to the ASA which we will now address. It is important to keep in mind that many of the observations made are equally applicable to advertising standards in a number of countries.

The first referral to the ASA was made by the QAA in relation to certain aspects of the advertising used by UK Essays. The ASA ruling on All Answers Ltd. t/a UK Essays was delivered on 21.3.18 (ASA 2018) and related to not uncommon advertising:

"The home page featured text that stated "... GUARANTEED GRADE, EVERY TIME We're so confident you'll love the work we produce, we guarantee the final grade of the work. Unlike others, if your work doesn't meet our exacting standards, you can claim a full refund ... LOVED BY CUSTOMERS \& THE GLOBAL PRESS UK Essays have lots of press coverage from all over the world confirming that a 2:1 piece of work produced by us met this standard... We were the first company in the world to offer you guaranteed 2:1 and 1st class work". 
Additional information about the service was included on pages titled 'WORLD CLASS GUARANTEES' and 'UK ESSAYS IN THE PRESS'.

The QAA asserted that:

1. The advert was misleading, because they believed it did not make sufficiently clear the risks associated with submitting purchased essays; and

2. The references to the press coverage that UK essays received misleadingly implied that they had received positive coverage or endorsement from those press outlets.

The ASA considered that consumers would expect from the advert that they could submit purchased essays as their own that would meet the ordered grade without risks, which was not the case. They therefore concluded that the advert was misleading and the complaint was upheld. Furthermore, the ASA considered that the manner in which the quotes were presented was likely to give an overall impression that UK Essays received positive reviews or coverage from the sources referred to and again the complaint was upheld.

Interestingly, in relation to the point made on press coverage above, when accessed on the 16 July 2019, there is a quote on the UK Essays website on the 'press coverage' tab from The Guardian newspaper (a quality UK broadsheet). It reads "if you consider that the difference between $a 2.1$ and a 2.2 can be thousands of pounds on your starting salary, the incentives are obvious". This quote may suggest that using the services of UK Essays has a value. The quote is taken from a Boris Johnson article in 2006 (Johnson, 2006 written before his elevation to UK Prime minister) in which he refers to 'cheats' and that it makes him feel 'queasy'.

As UK Essays stated in its response to the ASA investigation, the original press publications are readily available on their press coverage tab. However, the Boris Johnson article is available at the very end of the page, in much less bold text. Arguably, it is harder to find than other articles. The article is entitled 'the unbearable triteness of cheating'. The quote they have used certainly does not seem to match the general tone of the article and a customer might think that UK Essays had received a positive review in this article.

The ASA explicitly directed UK Essays to stop presenting advertisements from press coverage and other published sources in a manner that was not reflective of the tone and content of those sources. This may not have been acted upon.

There has been another QAA referral in relation to the advertising by Essay Writing Services UK. The ASA ruling against Thoughtbridge Consulting Ltd. was delivered on 7.11.2018 (ASA 2019a). The similar issue of being able to submit the essay as your own essay was flagged, as well the grade guarantee advertisement.

"the home page included text on the home page which stated "Get the grades you Need and Achieve More Today! ... GRADE GUARANTEE Get the grade you ordered first time, or your money back Plagiarism Free, Free plagiarism report with every order ... Only for you The work you order will never be re-used or re-sold".

It was asserted that:

1. "Get the grade you ordered", "Plagiarism free" and "The work you order will never be re-used or re-sold" misleadingly implied that consumers could hand the essay in as their own; and 
2. "Grade guarantee Get the grade you ordered" was misleading and could be substantiated.

The ASA considered that consumers would expect that they could submit purchased essays as their own without risks from the advert, which was not the case. They therefore concluded that the ad was misleading and the claim was upheld. Furthermore, they considered that whilst the information was available on the "Guarantees page", consumers could go through the process of purchasing an essay without being given this detailed information, and therefore it could be overlooked. It was further considered that it was not clear to consumers that the claim "Grade guarantee "Get the grade you ordered first time, or your money back" meant that if the consumer paid to have their work marked by Essay Writing Service UK and did not achieve the indicated grade they were eligible for a refund, rather than that if they handed in the essay they purchased it would achieve the grade for which they had paid. Therefore, the ASA concluded that the claim was misleading.

In our research the terms and conditions on Essay Writing Services UK could not be accessed. It is assumed one would have to put 'additional info' in on the order page to get to the terms and conditions. Given the fact it is hard to find any trace of any terms and conditions, it is considered that this would be an impediment for a student who is not actively looking for them.

The most recent ruling by the ASA was delivered on 9 January 2019 against The Oxbridge Research Group Ltd., known commonly as Oxbridge Essays (ASA 2019b). There were two separate issues, both being upheld. The website included claims on the home page which stated "With Oxbridge Essays, it has never been easier to get the grades you've always wanted ... First class? 2:1? No problem. We work with over 1,900 of the UK's best academics to make sure you get the grade you want ... Get better grades We'll send you the product you have ordered on your chosen delivery date - it's that simple". Further text on a page headed "Dissertation writing services" stated "We put the time and effort into making every piece of work we write the best it can be - and the results speak for themselves ... Your dissertation will include everything your university requires: introduction, research question, chapter outlines, literature review, methodology, analysis, recommendations and conclusion ... Whatever standard you choose, we guarantee the work will be to that standard ... Oxbridge-educated academics The vast majority of our writers have studied or taught at the UK's two best universities, Oxford and Cambridge".

It was asserted that:

1. The ad misleadingly implied that students could submit an essay they bought as their own; and

2. The claim "The vast majority of our writers have studied or taught at the UK's two best universities, Oxford and Cambridge" was misleading and could be substantiated.

The ASA considered that consumers would understand from the advert that they could submit purchased essays as their own without risks, and the website did not make sufficiently clear that was not the case, concluding that the advert was misleading 
and the claim was upheld. They also considered that consumers would interpret the claim 'the vast majority of our writers have studied or taught at the UK's two best universities Oxford and Cambridge" to mean that almost all of the writers who wrote for Oxbridge Essays had either completed a degree or taught at either Oxford or Cambridge universities. Given the fact only $71 \%$ of the writers had either studied or taught at Oxford or Cambridge, it was considered not to be sufficient to meet consumers expectation based on the advertising claim, that almost all writers had a degree from, or had taught at, one of those universities, and that it was more likely than not that an essay would be written by a writer from one of those universities. The ASA therefore concluded that the claim was misleading and again the claim was upheld.

Given the potential consequences of continuing to operate as usual in the context of the change in the law relating to the legal test of dishonesty and the ASA rulings it is reasonable to assume that a fundamental change to the business model of Essay Mills and the terms and conditions under which they operate would be evident. We therefore sought to assess and test this assumption by revisiting and expanding earlier research.

\section{Have essay Mills changed their business model?}

In the first 2017 article, the commonly observed practises of some UK based essaywriting companies along with their terms and conditions of supply were compared to sections 1-7 the UK Fraud Act 2006 to determine whether or not these companies were committing an offence under these sections of the Act.

Twenty six sites operated by 21 apparently distinct companies were analysed; each had separate listings at UK Companies House. The identity of the specific companies were not included for publication for the following reasons: 1. not wanting to further advertise the services of these companies, either through publication or through any publicity associated with it. 2. there was no guarantee that the company number given on these websites was actually that of the company which ran the site. In some cases, the names were the same but in others this was not the case. 3 . The content of the article was academic opinion and not the basis for legal proceedings. We have adopted the same principle in this article.

In July 2016, the websites of those companies (Table 1) were accessed to address a series of questions), which would then allow for consideration of the relevant sections of the Fraud Act. Questions were addressed by one author with cross checking by another. Table 1 is reprinted for ease of reference and comparison with new data.

In July 2019, we adopted the same methodology described above when updating results for the purposes of this article. The websites of those companies were accessed to address a series of questions (Table 2) which would then allow us to consider the relevant sections of the Fraud Act. Questions were addressed by one author with cross checking by a second. For the final question, "Is the advertising potentially misleading (compared to disclaimer/terms + conditions)?", the authors considered the advertising to be misleading if it (for example) gave an overall impression that work purchased from the site could be submitted as if it were a student's own work, without citing the company. A similar approach has also recently been adopted by the ASA, as we discuss below. 
Table 1 July 2016: Questions asked of the different websites and the number/percentage of sites for which the answered was considered to be 'yes'

\begin{tabular}{lll}
\hline Question & \# sites & $\%$ \\
\hline Is there a disclaimer of liability in respect of use? & 16 & 52 \\
Are there contractual terms and conditions relating to use? & 31 & 100 \\
Are customers able to specify the quality (grade) of the work)? & 20 & 65 \\
Is the Intellectual Property in the work retained by the company? & 15 & 48 \\
Does the work come with a 'plagiarism-free' guarantee? & 31 & 100 \\
Does the site state that the products are to be used for 'research' only? & 31 & 100 \\
Does the site offer 'qualified' or 'expert' writers? & 31 & 100 \\
Is the advertising potentially misleading (compared to disclaimer/terms + conditions)? & 8 & 31 \\
\hline
\end{tabular}

\section{Findings}

Our main conclusion is that UK registered essay mills have not significantly altered their terms and conditions since July 2016. However, there are some differences of note.

Six websites have either been taken down or not accessible since the original research, which explains the fewer number of sites considered by our current research.

There has been an increase in the number of websites which we consider to be misleading (gives the overall impression that work purchased from the site could be submitted as if it were a student's own work) having regard to advice given in the ASA rulings: a rise from $31 \%$ to $68 \%$. This is significant for our discussion on behaviours that might be objectively considered dishonest that follows later in this article.

As previously noted Essay Mills have a disclaimer in their terms of use on the website or in their terms and conditions. However, during our current research some terms and conditions could not be easily found, or personal details had to be registered in order to gain 'additional info' where it is assumed that terms and conditions are located. This too is an apparent change in practice and the reason for the percentage reduction in the tables from $100 \%$ to $88 \%$.

The plagiarism free guarantee and qualified writer guarantee are inducements that these websites continue to deploy but again with a notable reduction in relation to the plagiarism free guarantee (100\% offer down to $84 \%)$.

There is a reduction in the number of sites that allow a student to specify a grade. The reason for this may be explained by the fact that some companies guarantee a

Table 2 July 2019: Questions asked of the different websites and the number/percentage of sites for which the answered was considered to be 'yes'

\begin{tabular}{lll}
\hline Question & \# sites & $\%$ \\
\hline Is there a disclaimer of liability in respect of use? & 20 & 80 \\
Are there contractual terms and conditions relating to use? & 22 & 88 \\
Are customers able to specify the quality (grade) of the work)? & 13 & 52 \\
Is the Intellectual Property in the work retained by the company? & 15 & 60 \\
Does the work come with a 'plagiarism-free' guarantee? & 21 & 84 \\
Does the site state that the products are to be used for 'research' only? & 24 & 96 \\
Does the site offer 'qualified' or 'expert' writers? & 24 & 96 \\
Is the advertising potentially misleading (compared to disclaimer/terms + conditions)? & 17 & 68 \\
\hline
\end{tabular}


particular quality but not a grade. It would be inappropriate to characterise this as a 'grade guarantee'.

A point of note is that there is now one website which no longer offers academic writing. It only provides free essays and the terms and conditions specifically state that they no longer offer academic writing services. This might be attributable to the impact of the ASA rulings. It is certainly a welcome development.

\section{Changes in practice due to ASA rulings}

The issues identified by the ASA in relation to Essay Mill websites are not unique to the UK and will have much in common with sites in other jurisdictions such as Australia, New Zealand and the Republic of Ireland.

Our Findings from Table 2 note that have been changes and we have sought to contextualise these changes having regard to the key issues identified by the ASA. Therefore Table 3 identifies the key issues addressed by the ASA in their rulings against the three essay mills noted above. We have looked at the current content of all the UK registered websites researched (so far as we able to do so) and questioned whether they clearly adopt the spirit or intention of the rulings of the ASA. We offer a reminder at this point that our interpretation is academic opinion and not a basis for further action by the ASA or otherwise.

The ASA considered it critical that Essay Mills should make it clear to customers at the point of order that they cannot submit purchased work as their own without risks. Our review indicates that this crucial recommendation has not been adopted in the manner intended (bringing this to the attention of students at point of purchase) and that the companies continue to rely on their terms and conditions to avoid liability or to carry key injunctions in areas of the website away from the order page (and therefore potentially unread by a purchaser) whilst also using familiar inducements in relation to guarantees and press coverage but in a revised format.

In our academic opinion, UK registered Essay Mills may be non-compliant in varying degrees with the ASA guidance in their current format as Table 3 demonstrates. If so and having regard to the change in the law relating to the legal test of dishonesty the question arises whether or not Essay Mills are operating in a dishonest manner.

Table 3 July 2019: Have the websites of essay mills changed sufficiently to match the rulings of the ASA

\begin{tabular}{ll}
\hline Key Issues Addressed by ASA in their three rulings & $\begin{array}{l}\text { Percentage of Essay Mills which have been } \\
\text { researched who may not comply with the } \\
\text { spirit and intention of the ASA rulings. }\end{array}$ \\
\hline $\begin{array}{l}\text { Ad was misleading because they believed it did not make } \\
\text { sufficiently clear the risks associated with submitting purchased } \\
\text { essays }\end{array}$ & $76 \%$ \\
The references to the press coverage that UK Essays misleadingly & 12\% \\
implied that they had received positive coverage or endorsement \\
from those press outlets. \\
$\begin{array}{l}\text { Grade guarantee was misleading as it was not the case that any } \\
\text { grade bought could be guaranteed. }\end{array}$ \\
$\begin{array}{l}\text { Must ensure that they do not misleadingly imply that almost all of } \\
\text { their writers had studied or taught at specific universities. }\end{array}$ \\
\hline
\end{tabular}




\section{Are essay Mills operating dishonestly?}

The first point to note that although the majority of UK registered Essay Mills may have a website or advertising considered misleading for the purposes of advertising standards this does not of itself necessarily amount to dishonest behaviour for the purposes of the Fraud Act.

Essay Mill websites in the UK continue to provide familiar guarantees, for example, ' $100 \%$ plagiarism free' and they do not appear to prioritise on their order page a clear warning that that the essay should not be submitted as the customers' own work. Some websites draw attention to 'model answers' or are to be used 'to inspire one's own work'. However, this warning is not given prominence. Many outline this important injunction in the FAQ section or refer to it once in a small part of the home page. Having regard to the ASA rulings, such critical warnings should appear on the order page so that the student can clearly see it before committing to purchase. Does a failure to do so matter?

The answer is Yes. Although not inherently dishonest the above would be factors to be taken into account when making an objective finding of dishonesty. It should be remembered that any finding will depend upon the facts of and evidence available in any particular case.

Removing the entirely subjective second part of the two-stage test of dishonesty removes or at least lessens the possibility that an Essay Mill of questionable moral standing with their own personal code of honesty will escape liability under the Fraud Act. The key question then is would the behaviour and practice of an Essay Mill in a particular case be considered dishonest by the standards of ordinary decent people?

The answer to this question will depend not simply on terms and conditions of business or nuanced judgements as to the overall 'misleading' tone of the website. Significant weight will be attached to the direct inducements and 'chat' that often takes place between students and Essay Mill prior to purchase as to how the student may use the essay. It can be said with some certainty that statements or 'chat' as to permitted use or other inducements which contradict terms and conditions of business are likely to be viewed as dishonest. We tentatively suggest that the change in the law of dishonesty which took place at the end of 2017 does not appear to have had a significant impact on the terms and conditions of UK registered Essay Mills as evidenced by Tables 2 and 3 above.

However a cautionary note is that the test in Ivey takes into account the defendant's knowledge and belief, and therefore it is not a straightforward objective test and an outcome of a finding of dishonesty is not therefore entirely certain.

Whilst dishonesty is important for establishing the section 2 offence, another option that could be used to prosecute Essay Mills is Section 7 of the Fraud Act which makes it an offence to make, adapt, supply or offer to supply any article knowing that it is designed or adapted for use in the course of or in connection with fraud, or intending it to be used to commit or facilitate fraud. Section 8 extends the meaning of "article" so as to include any program or data held in electronic form. This should include an essay stored or supplied electronically by an Essay Mill. For a section 7 offence to be committed dishonesty on the part of the Essay Mill is not required, only knowledge of or an intention to commit or facilitate fraud will suffice. 
"Knowledge" in Section 7 (1) (a) is a strict requirement although in practice, the use to which the article (essay) can be put is likely to provide sufficient evidence of the Essay Mills state of mind. Furthermore, as noted above, the publicity and media attention over student use of supplied essays would lead to a reasonable conclusion that an Essay Mill has relevant knowledge for the purposes of the offence ie that the student will beyond doubt submit it is as their own work.

However, the manufacture of articles (essays) that are capable of being used in or in connection with fraud but have other innocent uses (eg study aids tutoring or proof reading services) will probably not fall foul of this section unless the manufacturer intends that the essays should be used in a dishonest way (Section 7 (1) (b)). The terms and conditions of business will mitigate against the commission of an offence as essays are usually required to be used in a legitimate manner although again publicity in connection with how students are actually used and some of the advertising used by some of the Essay Mills may mean that $\mathrm{s.7}$ is a viable prosecution option particularly again having regard to the 'chat' and other inducements prior to purchase noted above.

The key issue here relating to a guilty mind is that liability under s.7 depends on knowledge and intention rather than dishonesty. Does this matter? We have noted above that Ivey takes into account the defendant's knowledge and belief in concluding whether or not dishonesty exists so the concept of knowledge is as important for section 2 as it is for section 7 of the Act.

So, what is knowledge for the purposes of the criminal law? Stephen Shute, (2002) states that all (criminal) offences which incorporate 'knowledge' of a specified proposition as a necessary element for their commission appear to require that the 'known' proposition be true. Shute also makes reference to the doctrine of wilful blindness, set out in Roper v Taylor's Garage (1951 2 TLR 284, supported by R v Hall, 198581 Cr App 260), which suggested that 'shutting one's eyes to an obvious means of knowledge or deliberately refraining from making inquiries, the result of which the person does not care to have' is in law 'actual knowledge'. When supplying an essay does an Essay Mill refrain from making inquiries as to its use because they do not want to hear the answer that it will be used as a submission for an assessment - particularly given the common knowledge that must now exist as to likely use?

Deliberately not asking the question because you might not like the answer can be distinguished from merely neglecting to make inquiries. Neglecting to make inquiries is not knowledge (i.e. not asking a student what they intend to do with the essay will not amount to knowledge of the student's intention to submit the essay as their own if they do so).

However, Shute concludes that the doctrine of wilful blindness is and should be treated as anomalous, he makes reference to the decision in R v Moys, $(1984,79 \mathrm{Cr}$ App R 72) which seems to confirm that suspicion, even great suspicion, should not be held equivalent to belief. A belief must be correct in order to be considered knowledge. Otherwise, the exact definition of knowledge is not certain, and allows for flexibility depending on the context of the offence it is applied to.

Therefore, it is unclear what level of knowledge is required to establish criminal liability and it is unclear whether the doctrine of wilful blindness (I didn't ask whether the student was going to submit the purchased essay and therefore I didn't 'know' as my terms and conditions state that a student must not take this action) could be applied to knowledge in a criminal context. 
This all means that liability under the first limb of section 7 for writing or supplying an essay for use in connection with fraud may be difficult to establish in relation to an Essay Mill although each case would turn on its own facts and in particular the 'chat' that may have taken place between the Essay Mill and student before or at the time of transacting in relation to the use of the essay.

Section 7 in its second limb relies upon intention (an intention that the essay be used in connection with fraud) as the basis of liability. R v Woollin (1999 1 AC 82) sets out the generally accepted definition for intention. It has been accepted that intention means either acting to bring about a particular result or acting in the face of the acknowledged virtual certainty that a particular result will come about (direct/indirect intention). However, Lord Steyn clearly states that 'it does not follow that 'intent' necessarily has precisely the same meaning in every context in the criminal law. This means that intention may be taken to mean something other than purpose/foresight of virtual certainty in other contexts, such as under the Fraud Act. The key question here is whether or not Essay Mills intend an essay be used by a student in submission for an assessment.

In the context of media and other attention and the information required from students in relation to grade and essay title, then whilst arguably Essay Mills are wilfully shutting their eyes to the obvious it is by no means certain that there is sufficient proof for criminal liability under the second limb of section 7 on the basis that they intended the submission of the essay by the student. Their terms and conditions say something very differently but again, each case would turn on its own facts and the 'chat' that may have taken place between the Essay Mill and student before or at the time of transacting in relation to the use of the essay. These evidentiary challenges in relation to knowledge and intention are likely to mitigate against a prosecuting authority taking action under section 7 of the Fraud Act 2006.

\section{Is criminal prosecution likely?}

We have demonstrated that recent legal rulings make it easier to impute the knowledge of human agents to corporate Essay Mills and the context of QAA guidance and ASA rulings, as well as associated media attention, may assist in making a finding of dishonesty under the revised objective Ivey test in relation to the Fraud Act more likely. We have also demonstrated that other offences requiring knowledge and intention may be brought into play having regard to the chat and inducements that frequently occur prior to student purchase although the evidentiary challenges remain significant hurdles.

Furthermore action under the Fraud Act is on a case-by-case basis and requires the Crown Prosecution Service to bring a prosecution. The Crown Prosecution Rervice is a UK government agency employing lawyers who are responsible for examining police evidence, deciding whether to take criminal proceedings through to court prosecution stage and preparing cases for court and conducting prosecutions.

There are still a number of practical obstacles and questions to the use of the Fraud Act. The competing priorities of the Crown Prosecution Service is one such obstacle. An academic marking an essay becomes suspicious that a student has used an Essay Mill, does that academic become an investigator of a possible criminal offence? Should staff now call the police? How long would a case take and what would happen to the students and staff in the meantime? Where and how would evidence be collected; Does 
a university virtual learning environment become a crime scene? Many of these questions and practicalities arise because when the Fraud Act is applied; it would necessarily involve the student concerned and staff in determining whether there was a prima facie case and subsequently a successful prosecution.

These practical and evidential obstacles will militate against a criminal prosecution. If criminal prosecutions are unlikely due to practical and evidential challenges then these difficulties support the creation of a new criminal offence that is directed at the supply side and not the student demand side of the business model of Essay Mills.

\section{Argument for a new law}

For all of the above reasons, we maintain that a change in the law is required and that the central argument of the article 'A legal approach to tackling contract cheating? holds good.

Draper and Newton (2017) detailed a draft law, which could be used to outlaw the provision and advertising of essay writing services and would address the limitations identified above by targeting contract cheating at source; the Essay Mills themselves. This proposed new criminal offence relies on the legal principle of 'Strict Liability', which would simply make it an offence to offer contract cheating services, regardless of dishonesty, knowledge or intent.

There remains a strong public interest in ensuring that (for example) the doctor, engineer or lawyer has obtained their qualifications via learning they undertook themselves rather than bought from an Essay Mill. Essay Mills should not be able to obfuscate that 'the terms and conditions say students should only use our bespoke custom written plagiarism-free guaranteed grade assignments as a 'reference work.'

Strict Liability would ensure that the following is an offence:

"completing for financial gain or financial reward in whole or in part an assignment or any other work that a student enrolled at a Higher Education provider is required to complete as part of a Higher Education course in their stead without authorisation from those making the requirement".

This principle would be extended to include the arrangement and advertising of such services. A Strict Liability offence would reverse the burden of proof and place the cost of the defence on the Essay Mill - a mill would be guilty of a criminal offence by mere fact of supply unless they establish a defence which is a much stronger deterrent and an provides an easier route to prosecution.

To establish a defence of due diligence we suggest that an Essay Mill would as a minimum have to remove plagiarism free guarantees, cease writing to a specific title and grade and give a clear warning at the point of purchase as to permitted use of the essay and the risks of failing to comply. All pre-purchase chat and reassurances as to use which contradict terms and conditions of business would have to end. An Essay Mill might even be required to submit the essay to a database which could be searched by text matching software of the type used by educational institutions and advise a student purchaser that this would be done.

Recent research published by Newton (2018) in Frontiers in Education, demonstrates that Essay Mills continue to thrive with students continuing to use their services. Anna 
McKie writing in the Times Higher Education (Mckie 2018), notes that UK registered essay mills wilfully continue to trade as:

“...... essay mills are not illegal in the UK - as the UK Essays website points out, 'we would have been shut down a long time ago' if they were ... ...

The article by Draper and Newton (2017) was the only research cited to the then UK Education Minister in a 2018 letter signed by over 40 Vice Chancellors of UK Universities, calling for Essay Mills to be banned by the law.

Australia is seeking to pass new legislation (Amigud \& Dawson 2019) and the Republic of Ireland has recently done so. Both countries operate similar criminal offences in relation to fraud as the UK and both have elected to adopt new legislation to combat Essay Mills because of the challenges faced with using existing fraud laws.

The Republic of Ireland passed an Amendment Bill in July 2019, which introduces changes to the Qualifications and Quality Assurance (Education and Training) Act 2012. Section 43A of the Amendment Bill will provide a statutory basis for the prosecution of those who facilitate cheating by learners; who advertise cheating services and who publish advertisements for cheating services.

The Amendment Bill does not directly provide for extraterritorial effect but will enable conversations with platforms such as Google and Facebook that continuing to host 'marketing' and 'advertising' material for Essay Mills will be in breach of that platforms operational terms and conditions in relation to posting illegal material. Indirectly therefore extraterritorial effect is achieved.

In circumstances in which Essay Mills frequently operate across national boundaries this indirect outcome and the in-principle support offered by Jetvia v Bilta (2015) for the creation of an offence that has extra-territorial effect will alleviate concerns over displacement and off-shoring of Essay Mill services.

\section{Conclusion}

The continued complexities of the Fraud Act: the precise nature of the new objective test of dishonesty, the meaning of knowledge and intention for the purpose of certain offences and the application of these concepts alongside the terms and conditions of Essay Mill websites and the direct marketing and 'chat' to which students are subjected (often contradicting key terms and conditions), are strong arguments for bespoke legislation that avoids these complexities through utlilising the principle of strict liability in order to address contract cheating for financial gain. This is particularly the case if we are to avoid students being the subject of criminal prosecution (students could be caught by the revised test of dishonesty and thus commit fraud through submission of a purchased essay) and in order to focus the resource and attention of prosecuting authorities on Essay Mills.

Although welcome, we have also demonstrated through Tables 2 and 3, that the ASA rulings have not significantly changed the behaviours of UK registered Essay Mills. The only reasonable conclusion is that if we are to stop the activity of Essay Mills in the UK then we have to adopt the solution hinted at by UK Essays 2018 website - we have to make their services illegal.

We therefore submit that not taking action to create a new bespoke offence targeting Essay Mills in the UK in relation to contract cheating for financial gain and the advertising of such services is no longer an option. 


\section{Abbreviations}

ASA: Advertising Standards Authority; CPS: Crown Prosecution Service; QAA: Quality Assurance Agency

\section{Acknowledgements}

The authors acknowledge the contribution of Hannah Hutchison a law student intern in 2018 to the investigation of essay mill websites and background law upon which the data in this article is based.

\section{Originality and review status}

The authors confirm that this work is original and has not been published elsewhere, nor is it currently under consideration for publication elsewhere.

\section{Authors' contributions}

The authors are solely responsible for this article. Both authors read and approved the final manuscript. This article was written by the lead author with support from the second author who undertook the most current primary investigation of the essay mill websites upon which the data in this article is based. The methodology is described in the main body of the article.

\section{Funding}

Not applicable. There are no sources of funding for the research reported.

\section{Availability of data and materials}

The original research data upon which the Tables in this article are based is held by the Lead Author. The data will not be shared for the following reasons:

1. The data is based on academic opinion of publicly accessible documentation linked to UK registered companies. 2. We do not want to further advertise the services of these companies, either through publication or through any publicity associated with it. 3. We had no guarantee that the company number given on these websites is actually that of the company which runs the site. 4. The content of our article is academic opinion and not the basis for legal or other proceedings.

\section{Competing interests}

The authors declare that they have no competing interests.

Received: 6 August 2019 Accepted: 4 December 2019

Published online: 26 December 2019

\section{References}

Amigud A, Dawson P (2019) The law and the outlaw: is legal prohibition a viable solution to the contract cheating problem? Asses Eval Higher Educ. https://doi.org/10.1080/02602938.2019.1612851

ASA (2018) Advertising Standards Authority Ruling on Complaint Ref: A17-4. Retrieved November 23, 2019, from https:// www.asa.org.uk/rulings/all-answers-ltd-a17-394574.html

ASA (2019a) Advertising Standards Authority Ruling on Complaint Ref: A18-7. Retrieved November 23, 2019, from https:// www.asa.org.uk/rulings/thoughtbridge-consulting-ltd-a18-452244.html

ASA (2019b) Advertising Standards Authority Ruling on Complaint Ref: A18-10. Retrieved November 23, 2019, from https:// www.asa.org.uk/rulings/the-oxbridge-research-group-ltd-a18-458914.html

Draper MJ, Ibezim V, Newton PM (2017) Are Essay Mills committing fraud? An analysis of their behaviours vs the 2006 Fraud Act (UK). Int J Educ Integrity 13(1):3. https://doi.org/10.1007/s40979-017-0014-5

Draper MJ, Newton PM (2017) A legal Approach to tackling contract cheating. Int J Educ Integrity. https://doi.org/10.1007/ s40979-017-0022-5

Johnson, B. (2006) 'The unbearable triteness of cheating'. In The Guardian October 172006 Retrieved from https://www. theguardian.com/education/2006/oct/17/highereducationuk

McKie, A. 2018. 'Can Universities beat contract cheating?. In Times Higher Education September 132018 Retrieved from https://www.timeshighereducation.com/features/can-universities-beat-contract-cheating

Newton PM (2018) How Common Is Commercial Contract Cheating in Higher Education and Is It Increasing? A Systematic Review. Front Educ. https://doi.org/10.3389/feduc.2018.00067

QAA. (2016) 'Plagiarism in Higher Education - Custom Essay Writing Services: An Exploration and next Steps for the UK Higher Education Sector'

QAA (2017) "Contracting to Cheat in Higher Education - How to Address Contract Cheating, the Use of Third-Party Services and Essay Mills"

Shute S, Simester AP (2002) Criminal Law Theory. Oxford University Press; https://doi.org/10.1017/S0261387500013234

UK Government E (1986) Insolvency Act 1986 https://www.legislation.gov.uk/ukpga/1986/45/contents. Accessed 23 Nov 2019

UK Government E (2006) Fraud Act 2006 https://www.legislation.gov.uk/ukpga/2006/35/contents. Accessed 23 Nov 2019

\section{Publisher's Note}

Springer Nature remains neutral with regard to jurisdictional claims in published maps and institutional affiliations. 